\title{
Effect of ablation profile on wound healing and visual performance 1 year after excimer laser photorefractive keratectomy
}

Department of Ophthalmology, St Thomas's Hospital, London

M C Corbett

$S$ Verma

D P S O'Brart

G Heacock

J Marshall

Department of Optometry and Vision Science, Caledonian University, Glasgow KM Oliver

Correspondence to: Miss Melanie C Corbett, Department of Ophthalmology, St Thomas's Hospital (Block 8), Lambeth Palace Road, London SE1 7EH.

Accepted for publication 9 November 1995

Melanie C Corbett, Seema Verma, David P S O'Brart, Katherine M Oliver, Greg Heacock, John Marshall

\begin{abstract}
Background-Early photorefractive keratectomy ablations were of limited diameter and depth to maintain the integrity of the globe and to minimise postoperative haze. This study evaluated the effects of deeper, larger diameter wounds on refractive stability and corneal haze, and investigated the effects of ablation profile on wound healing and visual performance.

Methods-One hundred patients undergoing $-3 \cdot 00 \mathrm{D}$ and $-6 \cdot 00 \mathrm{D}$ corrections were randomised to receive $5 \mathrm{~mm}, 6 \mathrm{~mm}$, or multizone treatments. The multizone treatment was $6 \mathrm{~mm}$ in diameter, but only the depth of the $5 \mathrm{~mm}$ treatment. Outcome was measured by Snellen visual acuity, residual refractive error, objective techniques for haze and halos, pupil diameter, subjective night vision, and requirement for retreatment.

Results-Overall, the results of $6 \mathrm{~mm}$ treatments were superior to those of $5 \mathrm{~mm}$ and multizone treatments: they had a smaller hyperopic shift $(p<0.01)$, a more predictable $(p<0.001)$ and stable refractive outcome, less haze $(p<0.05)$, smaller halos $(p<0.05)$, fewer subjective night vision problems, and fewer patients required retreatment.

Conclusions-Analysis of these data and a literature review of corneal wound healing demonstrated that the improved outcome associated with the $6 \mathrm{~mm}$ beam did not relate to the depth of ablation. The factor with greatest apparent influence on the development of haze and regression was the slope of the wound surface over the entire area of the ablation. Tapering the wound edge provided no additional benefit, and contributed to night vision problems. It is, therefore, recommended that small diameter or multizone treatments should not be used in low and moderate myopia.

(Br f Ophthalmol 1996; 80: 224-234)
\end{abstract}

Photorefractive keratectomy (PRK) has now been the subject of clinical trials for over 5 years. One notable feature of the early studies was the variability of results between different treatment centres. ${ }^{1-9}$ Potential sources of variability could be divided into two main groups. The first comprised biological factors such as patient populations and varying surgical procedures, together with environmental cofactors. The second concerned mechanical aspects, including the physical characteristics of excimer laser ablations and the differences between commercial systems. From the literature, it is difficult to determine the relative contributions of any one factor, as studies frequently differ in more than one variable, and not all variables are necessarily controlled or reported. The aim of this study was to evaluate systematically the independent effects of ablation depth, diameter, and profile on the outcome of PRK at 1 year.

In the early studies of PRK, the depth of ablation was minimised for two reasons. The first was the theoretical concern that excessive ablation would weaken the integrity of the globe. ${ }^{1011}$ The second reason was the subjective impression that increasing depth of ablation was associated with greater postoperative haze. 249 12-16

In relation to the former, recent studies have shown that larger ablation diameters give a more predictable short term refractive outcome, ${ }^{17}$ but these larger wounds may produce greater disturbances in the structural integrity of the stroma. ${ }^{18-21}$ The present study investigated whether larger diameter treatment zones required more time to reach a stable outcome.

Systematic studies of haze failed to confirm a relation between haze and ablation depth $^{1} 2522-25$ and suggested that the depth of ablation was compounded by the severity of the pre-existing myopia. ${ }^{3}$ In addition, inconsistencies in the early work could have arisen from the lack of objective methods available to assess haze. The present study aimed to resolve these discrepancies by varying the ablation depth for a given dioptric correction, and by quantifying objectively corneal haze.

Many of the early studies used small diameter beams in order to minimise the depth of stroma removed. ${ }^{26}$ Some commercial systems with beam diameters in the region of $4 \mathrm{~mm}$ were typified by relatively large initial hyperopic shifts, followed by a fairly rapid reduction in hyperopia to a plateau, which was nearest emmetropia in the lowest order corrections. 13489 In these studies, the principal visual problem postoperatively was halos around lights at night, and in $10-15 \%$ of cases this was classed as severe. ${ }^{348}$

In contrast, other commercial systems with beam diameters up to $6 \mathrm{~mm}$ were characterised by smaller hyperopic shifts; although regression still followed moderate and higher 
order corrections. 256 However, a major advantage seen in these studies over those with smaller diameter beams was the lower incidence and severity of visual problems at night.

Studies comparing different ablation diameters induced by a single laser suggested that night vision problems were not the result of differences between commercial lasers, but were dependent upon the diameter of ablation and patient factors. ${ }^{1727}$ Therefore, the aim of the present study was to determine whether further increasing ablation diameters could improve halos without compromising refractive stability or corneal transparency.

\section{Methods}

\section{PATIENT SELECTION}

Approval for the study was granted by the ethics committee. Following extensive counselling, 100 patients were recruited from volunteers over the age of 24 years who had stable myopia of around $-3 \cdot 00 \mathrm{D}$ or $-6.00 \mathrm{D}$, with astigmatism of less than $1.50 \mathrm{DC}$. Those with diabetes or connective tissue disorders were excluded, and the absence of ocular disease was confirmed by a full ophthalmic examination. Before entering the study, all patients gave fully informed consent.

\section{TREATMENT GROUPS}

Forty patients received $-3 \cdot 00 \mathrm{D}$ PRK and 60 patients received $-6 \cdot 00 \mathrm{D}$ PRK (demographic data in Table 1). Using a random numbers table, patients within each group were allocated randomly to the different ablation profiles: $5 \mathrm{~mm}$ or $6 \mathrm{~mm}$ in diameter for the group receiving $-3.00 \mathrm{D}$ corrections; and $5 \mathrm{~mm}, 6$ $\mathrm{mm}$, or multizone treatments for patients receiving $-6.00 \mathrm{D}$ corrections. The multizone treatment was a two stage procedure consisting of a $-5 \cdot 00 \mathrm{D}$ correction of $4.60 \mathrm{~mm}$ diameter, followed within 2 minutes by a concentric $-1.00 \mathrm{D}$ correction $6 \mathrm{~mm}$ in diameter. This gave an ablation which was the diameter of the $6 \mathrm{~mm}$ treatment, but only the depth of the 5 $\mathrm{mm}$ treatment, and the profile was more tapered at the periphery.

The ablation profiles were compared by plotting the depth of tissue removed at $0.5 \mathrm{~mm}$ intervals across the diameter of the wounds, according to the commercial ablation algorithm. The aspect ratio of each wound was calculated from the ratio of the maximum wound depth to the wound diameter.

Table 1 Demographic data of the five treatment groups

\begin{tabular}{lllllll}
\hline $\begin{array}{l}\text { Correction } \\
(D)\end{array}$ & $\begin{array}{l}\text { Treatment } \\
\text { zone } \\
(\mathrm{mm})\end{array}$ & $\begin{array}{l}\text { Depth } \\
(\mu \mathrm{m})\end{array}$ & $\begin{array}{l}\text { Number } \\
\text { of } \\
\text { patients }\end{array}$ & $\begin{array}{l}\text { Age (years) } \\
\text { Mean }(S D)\end{array}$ & $\begin{array}{l}\text { Sex } \\
(\% \text { male })\end{array}$ & $\begin{array}{l}\text { Preoperative refraction } \\
(\text { sph equiv, D)* } \\
\text { Mean }(S D)\end{array}$ \\
\hline-3.00 & 5 & 26 & 21 & $37 \cdot 0(8 \cdot 2)$ & 38 & $-3 \cdot 43(0 \cdot 56)$ \\
& 6 & 42 & 19 & $35 \cdot 7(7 \cdot 7)$ & 26 & $-3 \cdot 16(0 \cdot 28)$ \\
-6.00 & 5 & 62 & 20 & $38 \cdot 7(9 \cdot 7)$ & 40 & $-6 \cdot 62(0.92)$ \\
& Multizone & 62 & 19 & $37 \cdot 4(9 \cdot 4)$ & 52 & $-6 \cdot 96(0 \cdot 69)$ \\
& 6 & 78 & 21 & $37 \cdot 4(9 \cdot 8)$ & 43 & $-6 \cdot 67(0 \cdot 79)$ \\
\hline
\end{tabular}

${ }^{\star}$ sph equiv $=$ spherical equivalent in dioptres.

\section{SURGICAL PROCEDURE}

All patients were treated by a single surgeon during a 6 week period in August/September 1993. A single Summit Technology Omnimed excimer laser was used, with an emission wavelength of $193 \mathrm{~nm}$, a fixed pulse repetition rate of $10 \mathrm{~Hz}$, and a radiant exposure of $180 \mathrm{~mJ} / \mathrm{cm}^{2}$. The profile of the ablation was determined by computer controlled expansion of the aperture in an iris diaphragm. The epithelium was removed manually from an area $6.5 \mathrm{~mm}$ in diameter, and the laser procedure was performed as described previously. ${ }^{3}$

\section{POSTOPERATIVE REGIMEN}

Postoperatively homatropine $2 \%$ and chloramphenicol $1 \%$ ointment were applied, the eye was padded overnight, then chloramphenicol $0.5 \%$ was administered four times a day for 1 week. Analgesia was provided by two tablets of Coproxamol (dextropropoxyphene hydrochloride $32.5 \mathrm{mg}$ and paracetamol $325 \mathrm{mg}$ ) given immediately after treatment, then 6 hourly or as required for up to 3 days. No topical corticosteroids were prescribed as clinical trials have demonstrated that they confer no lasting benefit. ${ }^{162829}$

\section{PREOPERATIVE AND POSTOPERATIVE \\ EXAMINATIONS}

Detailed assessment of corneal function and visual performance was made preoperatively, and postoperatively at week 1 and months 1,3 , 6 , and 12. Refraction was measured by retinoscopy, subjectively with a fogging technique to accurately determine the end point, and by autorefraction (Nidek Autorefractor AR-1000). The results of these techniques were compared to determine whether the poor reliability of the autorefractor after $\mathrm{PRK}^{3}$ was improved following larger diameter treatments. The 'refractive change' was the difference between the preoperative and postoperative refraction. As emmetropia was not the aim of surgery in all cases, refractive results were expressed as 'residual refractive error', which is the difference between the actual refractive change and the intended refractive change.

Best corrected high contrast visual acuity was measured using a Snellen chart. Changes in visual acuity were expressed in terms of the number of lines on the chart lost or gained.

Corneal haze was assessed both objectively and subjectively. The objective measurement of haze was performed using equipment which has been described in detail elsewhere. ${ }^{30}$ This technique uses a charge coupled device (CCD) video camera and frame grabber to record corneal slit images. The haze was quantified by computer analysis of the grey scale level of the central cornea. Linear polarising filters were used to distinguish the component of the haze that was the result of back scattered light. This measure is related to forward scattered light which may in turn degrade the retinal image. ${ }^{31}$

Although the objective assessment of haze provides more accurate results, haze was also 
assessed subjectively to allow a more direct comparison to be made with data from other clinical centres. Subjective assessment was by slit-lamp biomicroscopy, and the intensity of the haze was graded from 0 to 4 as described previously. ${ }^{3}$

Subjective disturbance of vision at night was sought by direct questioning. Glare and halos were categorised as 'mild' if noticeable but tolerated or 'severe' if they resulted in functional disability such as prevention of driving at night or treatment of the second eye.

The halo experienced when viewing a bright target under standard conditions was measured objectively using a computer program. ${ }^{32}$ A central white disc on a dark background was displayed on a high resolution monitor. The outer edge of the halo seen around the white disc was delineated by moving a cursor centripetally along each of 12 fixed meridia until it touched the edge of the halo. The area bounded by these 12 points was calculated in square centimetres.

Apparent pupil diameter was measured preoperatively in darkness under standard conditions using an infrared pupillometer (VRB-100 binocular infrared videorefractor, Fortune Optical).

\section{REQUIREMENT FOR RETREATMENT}

At the 1 year appointment, the option of retreatment was discussed with those patients with a residual refractive error of more than $-2 \cdot 00 \mathrm{D}$, or a haze with a scattered light component of more than 70 grey scale units (approximately grade 2 ). The decision of whether to retreat was based on the patient's level of satisfaction and visual requirements, as well as the advice of the surgeon tailored to each individual case.

\section{STATISTICAL ANALYSIS}

Stability of refraction between 6 months and 1 year postoperatively was assessed by the number of patients in each group whose refraction had changed by $-0.25 \mathrm{D}$ over this period.

Comparison was made of the clinical outcome of the three treatment zones, for -3.00 and $-6 \cdot 00 \mathrm{D}$ corrections, at each time point. The $\chi^{2}$ test was used for nominal data (stability of refraction, subjective haze, subjective night vision), the Wilcoxon rank sum for ordinal

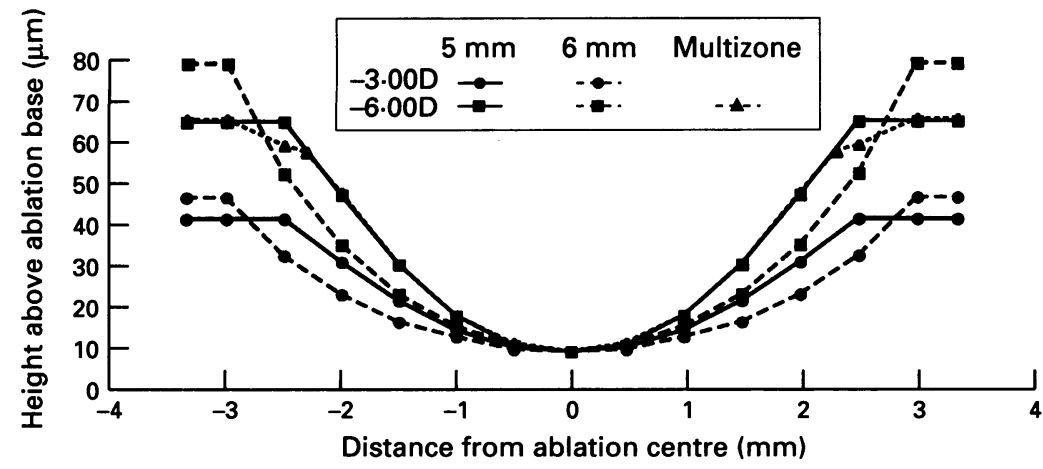

Figure 1 Ablation profiles of the five treatment zones demonstrating the influence of dioptric correction and zone diameter on the rate of change of slope of the wound surface. data and skewed ratio data (visual acuity, objective haze, objective halo), and the unpaired Student's $t$ test for normally distributed ratio data (residual refractive error). The predictability of the refractive outcome was analysed by calculating $F$ values to compare the variances of the different groups. The correlation function was determined for objective halo with treatment zone, pupil size, and refractive change.

\section{Results}

\section{WOUND PROFILE}

Figure 1 shows the profiles of some of the ablations used in this study. Of the single zone treatments, the rate of change of slope of the wound surface was greatest in the $-6 \cdot 00 \mathrm{D}$ $5 \mathrm{~mm}$ ablation. The surface slope was less steep in larger diameter ablations $(-6.00 \mathrm{D}$ $6 \mathrm{~mm}$ ), and particularly lower order corrections $(-3.00 \mathrm{D} 6 \mathrm{~mm})$. The multizone treatment, over most of its surface, had the steepest slope of all, but this was blended to the untreated cornea by an annulus with a shallow surface slope.

\section{CLINICAL RESULTS}

Overall, the results of the $6 \mathrm{~mm}$ treatments were superior to those of the $5 \mathrm{~mm}$ and multizone treatments: they had a more predictable and stable refractive outcome, less haze, smaller halos, and fewer night vision problems.
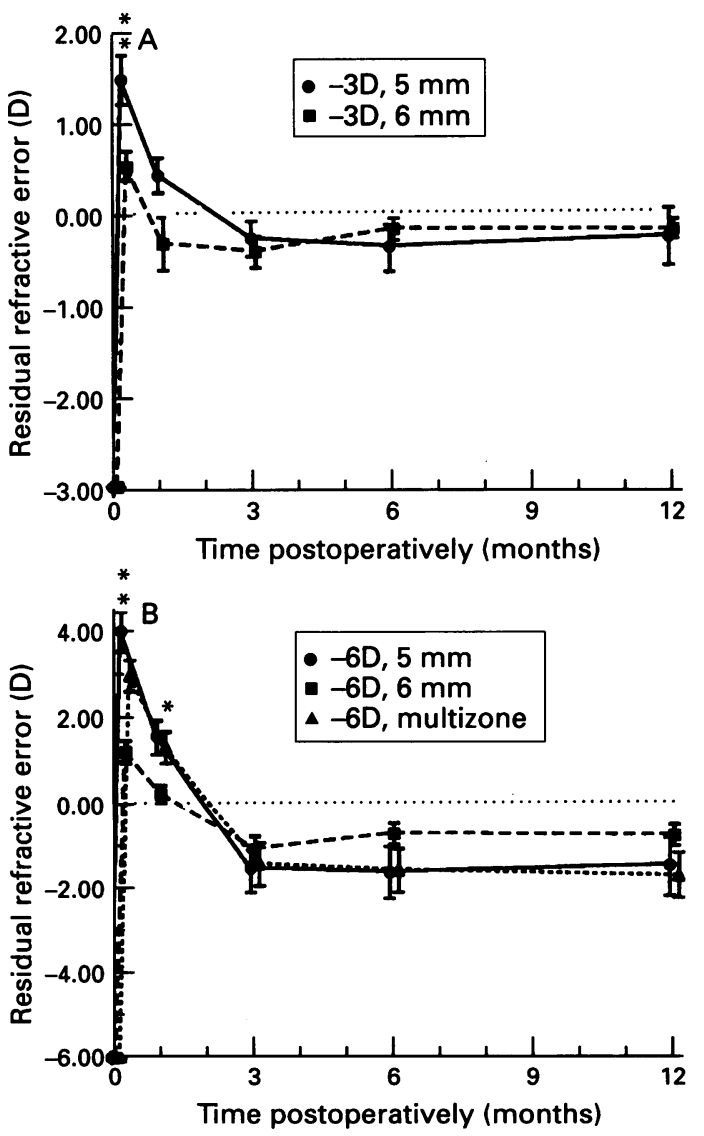

Figure 2 Residual refractive error for patients undergoing (A) $-3 \cdot 00 D$ and $(B)-6 \cdot 00 D$ corrections (mean (SE)); significance of the difference between the $5 \mathrm{~mm}$ and $6 \mathrm{~mm}$ treatments. ${ }^{*} p<0.05,{ }^{\star} p<0.01$. 
Table 2 Refractive outcome 1 year postoperatively for each of the five treatment groups, expressed as the percentage of patients whose residual refractive error was close to emmetropia (within plus or minus 1.00D), or showed unacceptable overcorrection $(>+1 \cdot 00 D)$ or undercorrection $(>-3.00 D)$

\begin{tabular}{lllll}
\hline & & \multicolumn{3}{l}{ Residual refractive error } \\
\cline { 3 - 5 } Correction & $\begin{array}{l}\text { Treatment } \\
\text { zone } \\
\text { (D) }\end{array}$ & $\begin{array}{l}\text { Good } \\
\text { outcome }\end{array}$ & \multicolumn{2}{l}{ Poor outcome } \\
\cline { 4 - 5 } \cline { 4 - 5 } & $(\mathrm{mm})$ & $\leqslant \pm 1.00 D$ & $>+1.00 D$ & $>-3.00 D$ \\
\hline-3.00 & 5 & 71 & 14 & 5 \\
& 6 & 100 & 0 & 0 \\
-6.00 & 5 & 20 & 20 & 25 \\
& Multizone & 26 & 11 & 21 \\
& 6 & 67 & 5 & 0 \\
\hline
\end{tabular}

\section{AUTOREFRACTION}

Postoperatively the autorefractor readings were not helpful, and inconsistent results were obtained in all treatment groups. Therefore we have relied upon subjective refraction.

\section{REFRACTION}

Patients in both the -3.00 and $-6.00 \mathrm{D}$ groups showed an initial overcorrection of the subjective refraction, followed by a return towards emmetropia (Figs $2 \mathrm{~A}$ and $2 \mathrm{~B}$ ). The hyperopic overshoot was significantly smaller in both dioptric groups in the patients receiving $6 \mathrm{~mm}$ treatments than in those receiving either $5 \mathrm{~mm}$ or multizone treatments, at 1 week $(p<0.01)$ and 1 month $(p<0.05)$
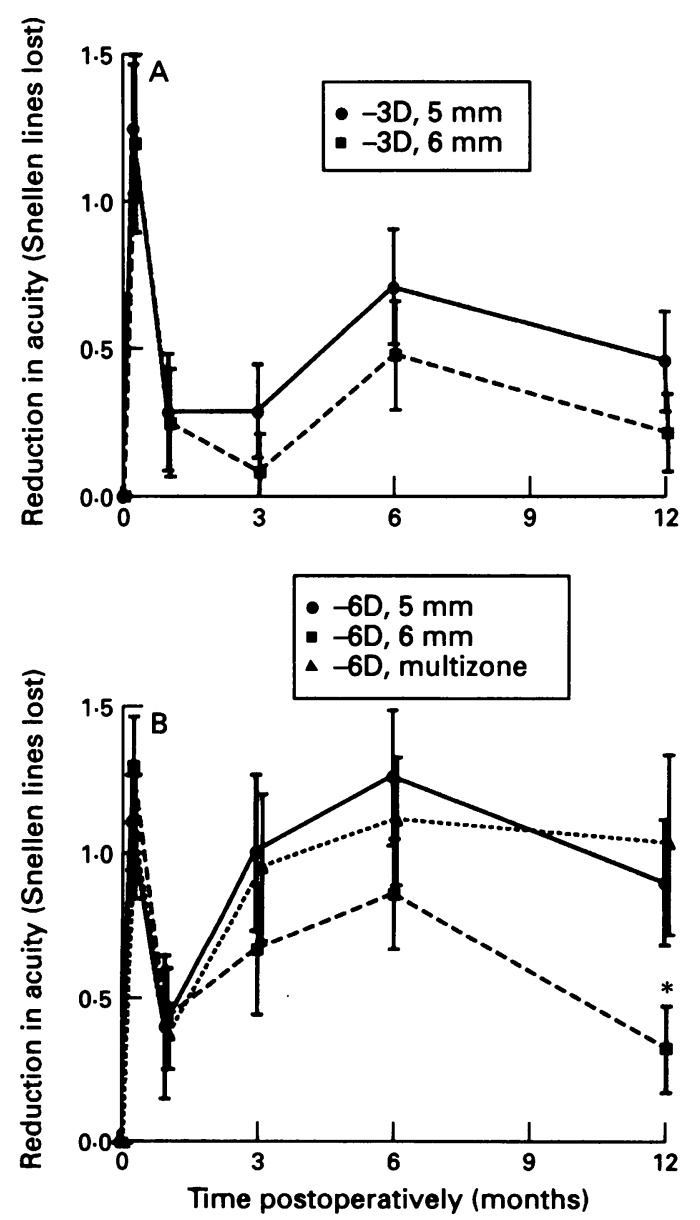

Figure 3 Reduction in visual acuity in terms of the number of Snellen lines lost for patients undergoing $(A)-3 \cdot 00 D$ and $(B)-6 \cdot 00 D$ corrections (mean (SE); significance of the difference between the $5 \mathrm{~mm}$ and $6 \mathrm{~mm}$ treatments. $\left.{ }^{\star} p<0.05\right)$. postoperatively. Thereafter, all groups showed further regression of the mean residual refractive error, to a plateau level at 3 months. Although this was nearer emmetropia in the $6 \mathrm{~mm}$ groups, the difference was not significant.

The predictability of the refractive outcome was significantly greater in the $6 \mathrm{~mm}$ groups than the $5 \mathrm{~mm}(\mathrm{p}<0.001)$ and multizone $(p<0.01)$ groups. This is demonstrated by comparison of the size of the standard error bars (Fig 2) and the proportion of patients within plus or minus $1.00 \mathrm{D}$ of the intended refraction (Table 2 ).

Stability of refraction between 6 months and 1 year postoperatively was greatest in the $6 \mathrm{~mm}$ groups and least in the multizone group.

\section{VISUAL ACUITY}

The transient reduction in visual acuity seen at 1 week was similar in the $-3.00 \mathrm{D}$ and $-6.00 \mathrm{D}$ groups, regardless of beam diameter (Figs 3A and 3B). This was followed by a second drop in acuity which appeared after 3 months, and was greater in the $-6.00 \mathrm{D}$ than in the $-3.00 \mathrm{D}$ corrections.

By 1 year, in both $-3.00 \mathrm{D}$ groups, mean visual acuity had improved to within half a line of preoperative levels. A similar improvement was seen for the $-6.00 \mathrm{D}$ group with the $6 \mathrm{~mm}$ beam. In contrast, for the $-6.00 \mathrm{D}$ groups with the $5 \mathrm{~mm}$ and multizone treatments, there was a persistent loss of one line of mean visual acuity. This was partly attributable to three and four patients respectively losing 2 or more lines of visual acuity, whereas no patients receiving $6 \mathrm{~mm}$ corrections had such a loss (Table 3 ).

\section{OBJECTIVE HAZE}

The CCD monitoring system showed that in all patients corneal transparency was reduced at 1 week. This appeared to be at the level of the epithelium or immediately below the epithelium, and was of similar severity in all treatment groups. It resolved by 1 month postoperatively (Figs 4A and 4B).

Over the next 3 to 6 months there was a more prolonged loss of transparency as corneal haze developed. When data from all the treatment groups were pooled, this was maximal at 6 months. If patients with high haze (greater than $1 \mathrm{SD}$ above the mean) were excluded from the analysis, the second peak loss of transparency occurred at 3 months in the majority of patients

Disturbances in both reflected and scattered light were significantly greater in the $-6.00 \mathrm{D}$ than the $-3.00 \mathrm{D}$ groups. The haze in the 6 $\mathrm{mm}$ groups was significantly less intense than in the $5 \mathrm{~mm}(\mathrm{p}<0.05$ to 0.01$)$ and multizone $(p<0.05)$ groups, and also appeared to be less prolonged. By 1 year, the mean haze had markedly reduced in all groups, although it still remained greater in the $5 \mathrm{~mm}(\mathrm{p}<0.01$ to 0.05 ) and multizone groups than in the $6 \mathrm{~mm}$ groups. 
Table 3 Complication rates 1 year postoperatively for each of the five treatment groups, expressed as the percentage of patients with loss of visual acuity or night vision problems. Severe haze as assessed by subjective means is recorded so these results can be compared with those of other published studies

\begin{tabular}{|c|c|c|c|c|c|c|}
\hline \multirow{2}{*}{$\begin{array}{l}\text { Correction } \\
\text { (D) }\end{array}$} & \multirow{2}{*}{$\begin{array}{l}\text { Treatment } \\
\text { zone } \\
(\mathrm{mm})\end{array}$} & \multicolumn{2}{|c|}{$\begin{array}{l}\text { Lost lines of Snellen } \\
\text { visual acuity }\end{array}$} & \multicolumn{2}{|c|}{$\begin{array}{l}\text { Subjective night } \\
\text { vision problems }\end{array}$} & \multirow{2}{*}{$\begin{array}{l}\text { Subjective } \\
\text { haze } \\
\geqslant 2+\end{array}$} \\
\hline & & $\geqslant 1$ Line & $\geqslant 2$ Lines & Mild & Severe & \\
\hline-3.00 & $\begin{array}{l}5 \\
6\end{array}$ & $\begin{array}{l}33 \\
26\end{array}$ & $\begin{array}{r}10 \\
0\end{array}$ & $\begin{array}{l}19 \\
10\end{array}$ & $\begin{array}{l}0 \\
0\end{array}$ & $\begin{array}{r}10 \\
0\end{array}$ \\
\hline$-6 \cdot 00$ & $\begin{array}{l}5 \\
\text { Multizone } \\
6\end{array}$ & $\begin{array}{l}55 \\
53 \\
33\end{array}$ & $\begin{array}{r}15 \\
21 \\
0\end{array}$ & $\begin{array}{l}10 \\
24 \\
14\end{array}$ & $\begin{array}{r}5 \\
14 \\
0\end{array}$ & $\begin{array}{r}25 \\
21 \\
0\end{array}$ \\
\hline
\end{tabular}

SUBJECTIVE HAZE

Within the first postoperative month, the majority of patients developed haze of grades 0.5 or 1 in severity. At 3 and 6 months a minority of patients had developed more severe haze (grades 2 to 4 ). This was more common after $-6.00 \mathrm{D}$ than $-3.00 \mathrm{D}$ corrections, and in the $5 \mathrm{~mm}$ and multizone groups.

By 1 year the haze tended to improve, with about one third of patients achieving clear corneas. However, there were still significant numbers of patients with $-6 \cdot 00 \mathrm{D}$ corrections
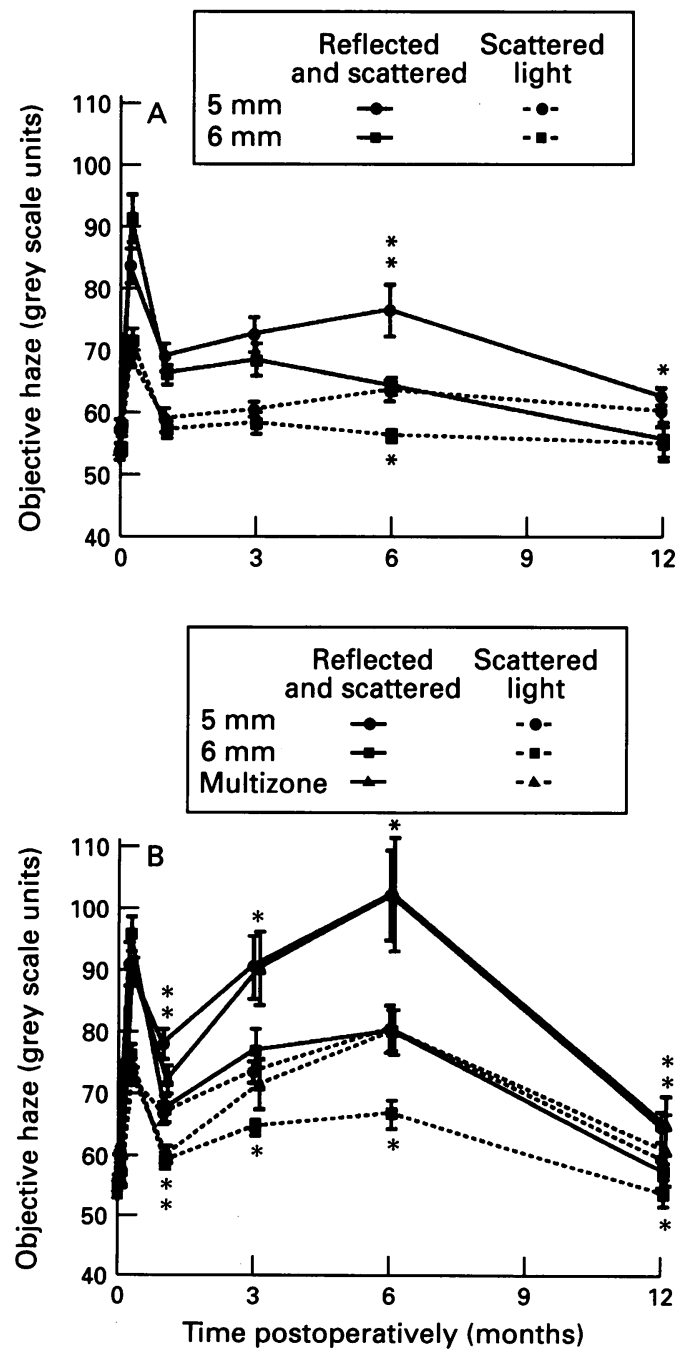

Figure 4 Objective haze for patients undergoing $(A)$ $-3 \cdot 00 D$ and $(B)-6 \cdot 00 D$ corrections. The combined reflected and back scattered values (solid lines) are an objective measure of haze as it appears to the observer. The back scattered component alone (broken lines) represents that component of the haze which interferes with the patient's vision. (Mean (SE); significance of the difference between the $5 \mathrm{~mm}$ and $6 \mathrm{~mm}$ treatments. ${ }^{\star} p<0.05$, ${ }^{\star}{ }_{p}<0.01$.) who retained haze of grade 3 or 4 (25\% of patients in the $5 \mathrm{~mm}$ group, and $20 \%$ in the multizone group). No haze of this severity was seen at 1 year in patients in the $6 \mathrm{~mm}$ groups (Table 3).

\section{REQUIREMENT FOR RETREATMENT}

Of the 18 patients who underwent retreatment, only one had received a $6 \mathrm{~mm}$ original treatment (Table 4). That patient had received a $-6 \cdot 00 \mathrm{D}$ correction, and the indication for retreatment was purely refractive. The remaining 17 patients had received either multizone (six patients) or $5 \mathrm{~mm}$ treatments (nine patients with $-6 \cdot 00 \mathrm{D}$ corrections, and two patients with $-3.00 \mathrm{D}$ corrections). In the majority of these cases, the indication for retreatment was both regression and haze. The need for retreatment was five times more common in the $-6.00 \mathrm{D}$ groups than the equivalent $-3 \cdot 00 \mathrm{D}$ groups.

\section{SUBJECTIVE NIGHT VISION}

There were no severe visual problems at night in any of the patients receiving $6 \mathrm{~mm}$ treatments. However, severe night vision problems did occur following $-6.00 \mathrm{D}$ corrections in the $5 \mathrm{~mm}$ (one patient) and multizone (three patients) treatment groups. Mild problems were also most common in these two groups (Table 3). There was no direct correlation of subjective difficulties in night vision with pupil size.

\section{OBJECTIVE HALO}

Objective halo was maximal 1 week postoperatively, then improved over the next 3 months (Figs 5A and 5B). At all time points halos were worse in patients in the $-6.00 \mathrm{D}$ than in the $-3.00 \mathrm{D}$ groups. At 1 week and 1 month, halos were significantly $(p<0.05)$ greater in $5 \mathrm{~mm}$ and multizone treatments compared with $6 \mathrm{~mm}$ treatments. Halos were a greater problem in those patients with large pupil diameters.

\section{Discussion}

The excimer laser (193 nm) was introduced into ophthalmology in the early 1980s, when it was realised that it had characteristics ideally suited to performing refractive surgery. ${ }^{1033}$ This laser could remove tissue with submicrometre precision, leaving a smooth surface with minimal damage to adjacent structures. ${ }^{34} 35$ The wide beam diameters allow the ablation of tissue from relatively large areas. ${ }^{10}$ Using this technique, it became possible to change the power of the cornea by the differential ablation of superficial tissue (PRK). This avoided the weakening of the globe associated with other popular refractive procedures such as radial keratotomy. ${ }^{21} 3637$

Early investigators were aware that physical aspects of the ablation may influence the biological wound healing response. The physical characteristics initially considered were pulse energy 
Table 4 Requirement for retreatment 1 year postoperatively for each of the five treatment groups, expressed as the percentage of patients in which the indication was for regression, haze or both

\begin{tabular}{|c|c|c|c|c|c|}
\hline \multirow[b]{2}{*}{$\begin{array}{l}\text { Correction } \\
\text { (D) }\end{array}$} & \multirow{2}{*}{$\begin{array}{l}\text { Treatment } \\
\text { zone } \\
(\mathrm{mm})\end{array}$} & \multicolumn{3}{|c|}{ Indication for retreatment } & \multirow[b]{2}{*}{ Total } \\
\hline & & $\begin{array}{l}\text { Regression } \\
(R R E>-2.00 D)\end{array}$ & $\begin{array}{l}\text { Haze } \\
(\text { Sc }>70 \text { units })\end{array}$ & $\begin{array}{l}\text { Regression } \\
\text { and haze }\end{array}$ & \\
\hline$-3 \cdot 00$ & $\begin{array}{l}5 \\
6\end{array}$ & $\begin{array}{l}5 \\
0\end{array}$ & $\begin{array}{l}0 \\
0\end{array}$ & $\begin{array}{l}5 \\
0\end{array}$ & $\begin{array}{r}10 \\
0\end{array}$ \\
\hline$-6 \cdot 00$ & $\begin{array}{l}5 \\
\text { Multizone } \\
6\end{array}$ & $\begin{array}{r}10 \\
0 \\
5\end{array}$ & $\begin{array}{l}5 \\
5 \\
0\end{array}$ & $\begin{array}{r}30 \\
26 \\
0\end{array}$ & $\begin{array}{r}45 \\
32 \\
5\end{array}$ \\
\hline
\end{tabular}

$R R E=$ residual refractive error; $\mathrm{Sc}=$ haze measured objectively in terms of backward scattered light; 70 grey scale units is approximately equivalent to $2+$ haze on subjective assessment.

and beam energy distribution, repetition rate, and area of initial ablation.

In order to limit ultrastructural damage, 223438 most groups elected to use an energy which was above the ablation threshold, but below that whereby residual energy could be converted into heat. In practice this means using a system between 120-200 $\mathrm{mJ} / \mathrm{cm}^{2} .3940$ At these levels, it has now been shown that there is little risk of injuring adjacent structures. The volume of tissue expelled from the surface by such energy levels has also been shown not to result in mechanical waves in the opposite direction of sufficient magnitude to damage the endothelium. ${ }^{41-43}$ At one time it was suggested that tangential excisions resulted in less haze than en face excisions because shock waves were not directed into the cornea ${ }^{44}$; however, any benefit would be
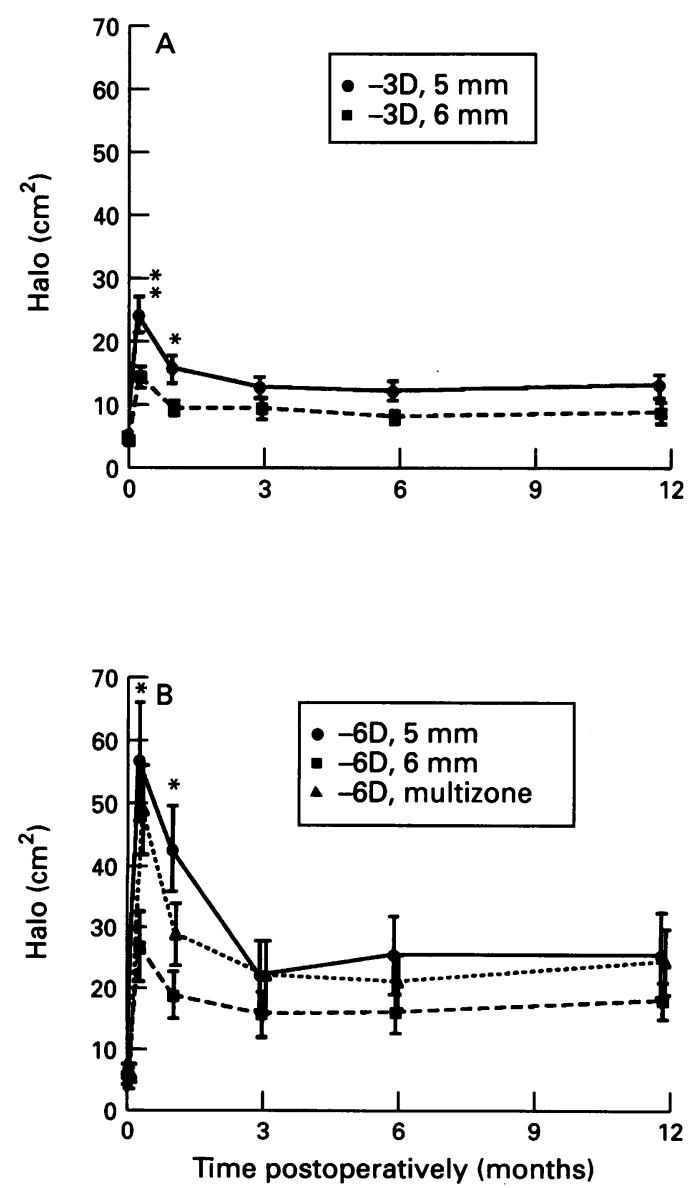

Figure 5 Objective halo for patients undergoing $(A)$ $-3.00 D$ and $(B)-6.00 D$ corrections. (Mean (SE); significance of the difference between the $5 \mathrm{~mm}$ and $6 \mathrm{~mm}$ treatments. ${ }^{\star} p<0.05,{ }^{\star}{ }_{p}<0.01$.) offset by potential thermal damage caused by repetitive exposure of the proximal wound edge.

Pulse frequencies were initially kept low $(5-10 \mathrm{~Hz})$ in order to minimise cross talk between pulses and tissue heating. It has since been suggested that higher pulse repetition rates produce clearer corneas, ${ }^{45}$ but this would require that ablation energies be further limited to avoid significant collateral heating. ${ }^{46}$

Finally, most groups elected to use small beam diameters for the first pulses of a treatment. This was, firstly, to ease centration and, secondly, to minimise the volume of tissue ablated and therefore the shockwaves and noise generated at the beginning of the treatment. In ultrastructural studies, expanding apertures were claimed to produce better surface regularity than contracting apertures. This was considered to be because the final laser pulse was applied to the whole treatment area, and therefore the pseudomembrane was in continuity, and not disrupted by pulses to adjacent tissue. ${ }^{47}$

The results of investigations such as these have determined some of the physical characteristics of ablations used today. However, there are other mechanical factors such as wound depth, diameter, and profile which still require investigation.

As PRK was the first technique in which tissue was permanently removed from relatively large areas of the central cornea, there was initial caution about the amount of tissue which could be safely ablated. There were two main areas of concern. Firstly, it was not known how much tissue should be left in situ to maintain the regularity and mechanical stability of the cornea after surgery. Secondly, it was possible that a larger wound would result in a greater wound healing response, which in turn might cause complications. Several studies have used ablation profiles of different shapes in order to limit the volume of tissue removed in the treatment of high myopia, 1920 48-52 but few so far have systematically evaluated which aspect of the wound shape accounts for the reported variations in clinical outcome. ${ }^{53}$

\section{DEPTH OF ABLATION}

Initially it was considered advisable to remove minimal amounts of tissue and, where possible, to preserve elements of Bowman's layer. ${ }^{54}$ In limiting ablations to within Bowman's layer, it was thought that the structural integrity of the cornea would be maintained, and also a smooth surface over which the epithelium could heal uniformly would be provided. ${ }^{10}$

From a mathematical model, Munnerlyn advised a maximal ablation depth of $50 \mu \mathrm{m}$ in order to avoid the summation of irregularities in the early beams, which he suggested would became obvious with deeper treatments. ${ }^{26}$ It now appears that summation of irregularities is unlikely, given the random interpulse variation in beam energy distribution. However, $50 \mu \mathrm{m}$ was also suggested as a maximum 
ablation depth following empirical studies of wound healing in monkeys ${ }^{12}$ and rabbits. ${ }^{13}$ Corneas remained clear after ablations of $50 \mu \mathrm{m}$ or less, but haze developed following deeper ablations. As a result of these animal studies, ablation depths in the first clinical trials were confined to the superficial one tenth of the stroma.

More recently, both experimental studies on animals and clinical observations have led to conflicting statements concerning the relation of haze to ablation depth. For example, while some animal studies suggested that postoperative haze increased with ablation depth, 121354 others showed no difference ${ }^{22}$ or the reverse relation. ${ }^{55}$ Subjective observations of haze in clinical studies have frequently reported greater haze in patients undergoing higher order corrections, ${ }^{49} 12-16$ but again other studies have found little correlation with the depth of ablation..$^{5-82-25}$ It has been suggested that the correlation reported in some studies may be compounded by the severity of pre-existing myopia. ${ }^{3}$ Further, the quantification of haze can be inconsistent in the absence of objective assessment techniques. ${ }^{30}$ The present study was able to resolve these discrepancies, firstly, by varying ablation depth for given dioptric corrections and, secondly, by using an objective method to measure haze.

\section{DIAMETER OF ABLATION}

For a spherical correction, the diameter of a PRK treatment zone is mathematically related to its depth for a given refractive change. ${ }^{26}$ Therefore, minimising the depth of ablation to conserve stroma requires that the treatment be of small diameter. The first clinical trials of excimer laser PRK used treatment zone diameters of $3.5 \mathrm{~mm},{ }^{4} 4 \mathrm{~mm},{ }^{356} 4.5 \mathrm{~mm},{ }^{6914}$ or $5 \mathrm{~mm} .{ }^{2} 614$ These produced fairly predictable refractive results, and in most patients, minimal to moderate haze. In practically all studies there were also a small number of patients in whom the haze was severe. Daytime visual performance was for the most part unaffected, but problems with vision at night were commonly recorded, 3489 and most patients described these as halos around lights.

Halos arose as a result of pupillary dilatation in dim illumination. ${ }^{32}$ 57-59 Under such conditions the retinal image was degraded by unfocused light passing through the untreated zone. In support of this concept, eyes with $5 \mathrm{~mm}$ ablation zones experience less halo at night than eyes with $4 \mathrm{~mm}$ zones. ${ }^{27}$ Therefore, there was interest in resolving halos by further increasing ablation diameters to an optimal level without compromising refractive stability or corneal transparency.

\section{REFRACTIVE STABILITY}

The structural integrity of the cornea is dependent upon the regular arrangement of tightly packed collagen fibres which are thought to run from limbus to limbus. ${ }^{6061}$ The orientation of the fibres, with those in adjacent lamellae running approximately perpendicular to each other, is considered to further enhance its structural stability. ${ }^{1862}$ Litwin studied how the mechanical stability of the cornea was affected by ablating to successively deeper levels in fresh human cadaver eyes. ${ }^{11}$ By maintaining the intraocular pressure synthetically, this study showed by photokeratoscopy that ablations of 50 and 100 $\mu \mathrm{m}$ produced corneal flattening while those of $150 \mu \mathrm{m}$ produced central steepening. The latter result was interpreted as bowing as a result of the intraocular pressure no longer being contained by the remaining lamellae.

In the present study, the theoretical maximum ablation depth was $78 \mu \mathrm{m}$ (the $-6.00 \mathrm{D}$, $6 \mathrm{~mm}$ group). This was the group that showed the greatest refractive stability between 6 months and 1 year, with over $50 \%$ of patients remaining within plus or minus $0 \cdot 25 \mathrm{D}$ of their refraction at 6 months. After 6 months, no group showed a tendency towards continued regression of refraction or increasing corneal curvature on topography. These results indicate that there was no steepening of the central cornea indicative of bowing because of mechanical instability or the production of new tissue.

\section{CORNEAL HAZE}

Slit-lamp examination with subjective analysis of haze has led to the concept that haze increases with depth of ablation. ${ }^{2} 4912-16$ This has not been sustained by objective analysis in this study, in which haze was significantly less in the $6 \mathrm{~mm}$ ( 39 or $78 \mu \mathrm{m}$ ) than the $5 \mathrm{~mm}$ ( 26 or $62 \mu \mathrm{m})$ and multizone $(62 \mu \mathrm{m})$ treatments, for a given dioptric correction. Other studies have also suggested that less haze occurs following larger diameter ablations. ${ }^{7} 1723$

In the present study there were five physical variables which could affect the nature of the initial wound, and therefore the wound healing response and resultant haze. These were: the depth, the diameter, the aspect ratio, the surface slope, and the profile of the edge of the ablation zone. By reviewing the literature concerning wound healing in the cornea it has been possible to propose cellular mechanisms by which each of these factors may be exerting an effect, and evaluate their relative importance.

\section{Ablation depth}

The reduction in haze seen in the $6 \mathrm{~mm}$ ablations could be related to increasing ablation depth, but this seems unlikely. In the corneas of most species, the deeper collagenous layers show greater order than the superficial layers. Therefore, the wound healing tissue produced by the deeper layers may have a more regular organisation and scatter less light. ${ }^{6364}$ However, this greater order occurs only in the posterior two thirds of the cornea, and would not be relevant to the results of the current study in which the maximum ablation depth was $78 \mu \mathrm{m}$; although it may apply to the deeper ablations used in phototherapeutic 
keratectomy. 2425 Deep ablations with relatively little haze are also seen following intrastromal techniques, ${ }^{22} 65$ but this is because stromal healing occurs without the influence of the epithelium, rather than being a direct function of depth.

\section{Ablation diameter}

Wounds of larger diameter differ from small diameter wounds in two main respects: firstly, there is a larger area of stromal ablation and, secondly, they involve more peripheral cornea. It has been suggested that stromal healing cannot take place until epithelial cover has occurred. ${ }^{22}$ If larger wounds took longer to epithelialise than small ones, this could theoretically explain why larger diameter ablations develop less haze. However, this is unlikely to be of practical importance in the present study for several reasons. Firstly, epithelial cells of peripheral origin regenerate faster than those of central origin. ${ }^{66}$ Secondly, the rate of epithelial migration is no slower over ablated than non-ablated cornea, ${ }^{67}$ partly due to the presence of a smooth pseudomembrane over the ablated surface. ${ }^{1034}$ Thirdly, epithelial migration is rapid, with the front moving at $2.5 \mathrm{~mm}$ per day and complete closure being achieved by the third postoperative day in the majority of patients. Therefore, an increase in wound diameter of $1 \mathrm{~mm}$ would delay epithelial closure by less than half a day, which is probably clinically insignificant. Fourthly, in this study the area of epithelial debridement was the same in all patients, regardless of the ablation diameter.

It has been shown in studies of full thickness incisions, that healing in the stroma was also faster peripherally than centrally. ${ }^{6869}$ If the faster healing rate in the periphery was the result of a more limited removal of damaged tissue in the early phases of wound healing, this may reduce the subsequent repair and replacement phases which result in corneal haze. However, there is little experimental or clinical evidence to suggest that the cornea scars less in the periphery than the centre. Therefore, haze is unlikely to be directly dependent on wound diameter.

\section{Wound aspect ratio}

The aspect ratio of a wound to some extent determines the type and amount of new tissue which is produced. The nature of that tissue is determined by the division and migration rates of the various cell types involved. ${ }^{70}$ The rapid division and migration of epithelial cells enables them to cover wounds in a short amount of time. This may be followed by remodelling with limited replacement by extracellular components. ${ }^{6869}$ There is a tendency for the wound healing tissue to generate a smooth surface, thus a deep narrow wound will be filled in to a greater extent than a large shallow wound, as demonstrated by radial keratotomy incisions ${ }^{69}$ or discrete corneal ulcers.

\section{Wound slope}

Related to the aspect ratio of a wound is the slope of the wound surface. For a given algorithm, there is a greater rate of change of slope in higher order corrections and when using smaller diameter treatment zones. Both of these wound variables are associated with more severe haze. The concept of increasing haze with the steepness of the ablation surface is supported by the extreme case of square edged keratectomies in which there is loss of transparency associated with the vertical wound edges, but not the horizontal base where few collagen fibres are transected. ${ }^{22}$ Likewise, tangential excisions have less haze than those performed en face, ${ }^{44}$ which may be because these wounds lack a vertical edge.

A possible explanation of these observations may be that the severity of haze is related to the number of adjacent collagen lamellae transected in a given area. ${ }^{34} 71$ Light microscopic studies of vertical incisions have demonstrated that there is a period during healing in which the keratocytes aggregate between collagen lamellae at the wound margins, disturbing its stereospatial relations. ${ }^{69}$ In the first 3 months after PRK, haze has been shown to be associated with changes in the keratocytes beneath the ablation site. These activated cells become larger and increase in density, ${ }^{31}$ and may thereby also alter the spacing and regularity of the stromal collagen, particularly where transected collagen fibres now have free ends. The keratocytes exposed between transected collagen fibres at the wound edge may be the ones responsible for synthesising the subepithelial glycosaminoglycans which also contribute to haze. ${ }^{73}$ The thickness of the epithelium (and therefore regression) may also be affected by the slope of the wound surface.

The importance of this concept can be further assessed by analysing corneal transparency as a function of the step size in a PRK wound. In laser systems using the movement of an aperture to determine the ablation profile, the wound surface has a substructure consisting of a series of steps. If the aperture moves with each pulse, the height of the steps is determined by the depth of tissue removed by a pulse $(0.25 \mu \mathrm{m})$, and the step width is determined by the excursion of the diaphragm between pulses.

Surface smoothness was initially considered to be of importance in minimising haze. ${ }^{1026344771}$ Some studies have demonstrated more severe haze in PRK wounds with a few larger steps than those which had a greater number of small steps, ${ }^{45}$ but others have failed to confirm this. ${ }^{22}$ It has been suggested that if the steps are sufficiently small for example, the depth of a single laser pulse $(0.25 \mu \mathrm{m})$, no epithelial hyperplasia would occur. ${ }^{13}$ However, other investigators have seen transient epithelial hyperplasia ${ }^{38}$ or haze ${ }^{73-75}$ in completely smooth wounds made by moving slits ${ }^{38}$ or erodible masks. ${ }^{73-75}$ One problem with comparing these results was that the analysis of haze was performed at different times often by subjective means, and therefore no firm conclusions could be drawn. 
Alternatively, there may be a critical step size below which changes in contour cannot be recognised by the cellular components in the system. The height or the width of the steps may be important, and wound healing may be dependent upon the aspect ratio of the steps and the size of the cells reacting to the steps. ${ }^{61}$

\section{Edge profile}

A sudden change in wound contour, as occurs at the edge of an ablation, may modulate wound healing. Such modulation may take the form of epithelial hyperplasia which tends to smooth out surface irregularities, or an exaggerated subepithelial response. ${ }^{12}$

In this study, the effect of edge profile was investigated independently of wound diameter or depth by using a multizone treatment. A small diameter ablation providing most of the dioptric correction was overlaid by a large diameter low dioptre correction to create a peripheral blend zone with only a gradual change in surface slope. The haze and regression which followed this multizone treatment were very similar to that resulting from the $5 \mathrm{~mm}$ treatment, and significantly greater than that seen with the $6 \mathrm{~mm}$ treatments. This aggressive wound healing may have occurred as a result of other factors which were not initially considered important. For example, 1 minute elapsed between the two portions of the multizone treatment while the laser was reprogrammed for the second stage. During this interval, surface evaporation may have occurred resulting in differential hydration across the wound site and variable rates of ablation. ${ }^{76}$

From our data and a review of the literature on corneal wound healing, we conclude that corneal haze is not a direct function of the depth or diameter of the wound, and nor is surface smoothness of major importance within certain limits. We feel that the factor with greatest influence on the development of corneal haze is the slope of the wound surface, particularly over the centre of the ablation. It appears that tapering the wound edge in the manner performed in this study is of no additional benefit.

\section{VISUAL ACUITY}

Changes in visual acuity tended to reflect the development and resolution of corneal haze. The transient loss of transparency and acuity seen in the first week was similar in all five treatment groups. This is therefore likely to be related to epithelial irregularity on the corneal surface.

The second drop in acuity occurring after 3 months was larger in the $-6.00 \mathrm{D}$ than the $-3.00 \mathrm{D}$ corrections. At this time, the haze was thought to be due to keratocyte disturbances, ${ }^{31}$ and the subepithelial deposition of glycosaminoglycans. ${ }^{72}$ In the $6 \mathrm{~mm}$ treatment groups the subepithelial deposit tends to resolve and the mean visual acuity returns to within half a line of preoperative levels. However, in the 5 $\mathrm{mm}$ and multizone treatments there were a clinically significant number of patients in whom the haze persisted causing a prolonged reduction in visual acuity.

\section{NIGHT VISION}

After PRK, visual problems at night arise from two distinct mechanisms: glare and halos. ${ }^{57} 58$ Glare is due to the forward scattering of light by corneal haze. Halos are myopic blur circles formed when the pupil dilates beyond a critical size, allowing light to pass through two or more separate refracting regions on the surface of the cornea.

The reduction in subjective night vision problems seen in the $6 \mathrm{~mm}$ treatment groups compared with the $5 \mathrm{~mm}$ groups was the result of improvements in both glare and halos. The reduction in the size of the objective halo was related to the increase in the diameter of the treatment zone. It is therefore possible that if treatment zones were enlarged sufficiently, the problem of halos could be eliminated completely. In this study, the majority of patients had a pupil diameter in darkness of less than $9 \mathrm{~mm}$ (mean $+2 \mathrm{SD}$ ). On this basis, the smallest beam diameter required to eliminate halos would be $7.5 \mathrm{~mm}$ for $-6.00 \mathrm{D}$ corrections, and even larger for higher order treatments. There is also the possibility that the use of larger diameter beams may further improve corneal haze, and with it, symptoms of glare and reduced visual acuity.

The multizone treatment was also $6 \mathrm{~mm}$ in diameter, but the objective halo was no better than after the $5 \mathrm{~mm}$ treatments. This may relate to the ablation profile. Many treatment zones consist of two portions. The optical zone is the part with the desired optical correction, and may be significantly smaller than the treatment zone (for example, $3.5 \mathrm{~mm}$ in a $5 \mathrm{~mm}$ ablation). ${ }^{77}$ This is surrounded by the transition zone of lesser power, which connects the optical zone to the untreated cornea. ${ }^{59}$ In the multizone treatment, the optical zone was provided by the $4.5 \mathrm{~mm}$ diameter component of the treatment; the $6 \mathrm{~mm}$ diameter component of the treatment only served to smooth the transition between the treated and untreated cornea. Nowadays, some centres are studying multizone treatments with a greater component of the correction in the larger diameter zone.

Subjective night vision following the multizone treatment was substantially worse than following the $5 \mathrm{~mm}$ treatment, despite producing objective halos and haze of a similar magnitude. This too may be explained by the ablation profile. ${ }^{78-82}$ The optical zone was surrounded by the transition zone of the 4.5 $\mathrm{mm}$ diameter component then a $1.5 \mathrm{~mm}$ annulus of the $6 \mathrm{~mm}$ diameter component. This resulted in a wide blend zone of dioptric power between that of the optical zone and the untreated cornea. Light passing through the blend zone would be focused less sharply than that passing through the optical zone, but to a greater extent than light passing through the untreated region. It would therefore result in an intense halo of semifocused 
light which could degrade the retinal image to a greater extent than a larger more diffuse halo.

If the size of a halo is related to the size of the optical zone, then the diameter of the optical zone should be increased. Seiler achieved this by using an aspheric algorithm which produced a greater power change in the mid periphery of the treatment zone than the centre, at the expense of the transition zone. ${ }^{77}$ This resulted in a rapid change in contour at the wound edge, which could (following the discussion above) have resulted in greater peripheral haze. However, if the diameter of such an ablation is sufficiently large, and the floor in the centre is sufficiently flat, haze may be confined to the wound edge, and the central cornea may remain relatively clear and provide good vision.

\section{ADDITIONAL BENEFITS OF LARGE DIAMETER BEAMS}

This study achieved its initial aim by demonstrating that the use of larger diameter treatment zones can reduce postoperative halos without compromising corneal stability or transparency. In fact less haze occurred after $6 \mathrm{~mm}$ than after $5 \mathrm{~mm}$ treatments.

Unforeseen additional benefits of larger diameter beams were a reduction in the hyperopic shift and improved predictability of the refractive outcome.

The hyperopic shift present in the first couple of months after surgery is due to a combination of excessive central corneal flattening while the epithelium is thin, and a ring of local steepening due to the synthesis of new tissue in the periphery of the treatment zone. ${ }^{12}$ This latter effect is probably less evident in larger ablations with more gently sloping wound edges. The resultant reduction in anisometropia may be helpful in maintaining stereopsis while waiting for treatment of the second eye.

Treatments by larger diameter beams showed better predictability of the refractive outcome, and also less variation in the severity of haze. In the past, Durrie had attributed the wide spread of data points to biological differences in wound healing. ${ }^{83}$ The reduction in interindividual variation seen in the current study suggests that the physical characteristics of the ablation profile can limit the effects of biological variation.

In view of the great biological and functional benefits gained by increasing the treatment zone diameter from $5 \mathrm{~mm}$ to $6 \mathrm{~mm}$, it will now have to be considered how much further ablation diameters will need to be increased to continue improving the clinical outcome of PRK without introducing adverse effects.

Miss Corbett holds The Williams Fellowship for Medical and Sceintific Research of the University of London.

The Iris Fund for Prevention of Blindness sponsored research fellowships for Mr O'Brart and Miss Verma, and provided financial support for the project.

Professor Marshall is a consultant for Summit Technology. The authors are grateful to Mrs Ann L Patmore for technical support, and to Summit Technology for making their ablation algorithms available.
1 Seiler T, Kahle G, Kriegerowski M, Bende T. Excimer laser $(193 \mathrm{~nm})$ myopic keratomileusis in sighted and blind human eyes. Refract Corneal Surg 1990; 6: 165-73.

2 Zabel RW, Sher NA, Ostrov CS, Parker P, Lindstrom R. Myopic excimer laser keratectomy: a preliminary report. Refract Corneal Surg 1990; 6: 329-34.

3 Gartry DS, Kerr Muir MG, Marshall J. Photorefractive keratectomy with an argon fluoride excimer laser: a clinical study. Refract Corneal Surg 1991; 7: 420-35.

4 Seiler T, Wollensak J. Myopic photorefractive keratectomy with the excimer laser: 1 year follow-up. Ophthalmology 1991; 98: 1156-63.

5 Sher NA, Chen V, Bowers RA, Frantz JM, Brown DC, Eiferman R, et al. The use of the 193nm excimer laser for myopic photorefractive keratectomy in sighted eyes. A multicentre study. Arch Ophthalmol 1991; 109: 1525-30.

6 McDonald MB, Liu JC, Byrd TJ, Abelmegeed M, Andrade $\mathrm{HA}, \mathrm{Klyce} \mathrm{SD}$, et al. Central photorefractive keratectomy for myopia. Ophthalmology 1991; 98: 1327-37.

7 Brancato R, Tavola A, Carones F, Sciaidone A, Gallus G, Fontanella G. Excimer laser photorefractive keratectomy (PRK): first report from the Italian study group. Ital $\mathcal{F}$ Ophthalmol 1991; 3: 189-95.

8 Gartry DS, Kerr Muir MG, Marshall J. Excimer laser photorefractive keratectomy: 18 month follow-up. Ophthalmology 1992; 99: 1209-19.

9 Tengroth B, Epstein D, Fagerholm P, Hamberg-Nyström H, Fitzsimmons TD. Excimer laser photorefractive keratectomy for myopia: clinical results in sighted eyes. tectomy for myopia: clinical result

10 Marshall J, Trokel S, Rothery S, Krueger RR. Photoablative reprofiling of the cornea using an excimer laser: photorefractive keratectomy. Lasers in Ophthalmol 1986; 1: 21-48.

11 Litwin KL, Moreira H, Ohadi C, McDonnell PJ. Changes in corneal curvature at different excimer laser ablative depths. Am ₹ Ophthalmol 1991; 111: 382-4.

12 Marshall J, Trokel S, Rothery S, Krueger RR. Longterm healing of the central cornea after photorefractive keratectomy ing of the central cornea after photorefractive keratectomy

13 Goodman GL, Trokel SL, Stark WJ, Munnerlyn CR, Green WR. Corneal healing following laser refractive keratectomy. Arch Ophthalmol 1989; 107: 1799-803.

14 McDonald MB, Frantz JM, Klyce SD, Beuerman RW, Varnell R, Munnerlyn CR, et al. Central photorefractive keratectomy for myopia: the blind eye study. Arch Ophthalmol 1990; 108: 799-808.

15 Liu JC, McDonald MB, Varnell R, Andrade HA. Myopic excimer laser photorefractive keratectomy: an analysis of excimer laser photorefractive keratectomy: an analysis of
clinical correlations. Refract Corneal Surg 1990; 6: 321-8.

16 Gartry DS, Kerr Muir MG, Lohmann CP, Marshall J. The effect of topical corticosteroids on refractive outcome and corneal haze after photorefractive keratectomy. Arch Ophthalmol 1992; 110: 944-52.

17 O'Brart DPS, Corbett MC, Lohmann CP, Kerr Muir MG, Marshall $\mathrm{J}$. The effects of ablation diameter on the outcome of excimer laser photorefractive keratectomy (PRK): a prospective, randomised, double blind study. Arch Ophthalmol 1995; 113: 438-43.

18 Buzard KA. Introduction to biomechanics of the cornea. [Review] Refract Corneal Surg 1992; 8: 126-38.

19 Tavola A, Brancato R, Galli L, Carones F, Esente S. Photorefractive keratectomy for myopia: single vs doublezone treatment in 166 eyes. Refract Corneal Surg 1993; 9 (Suppl): S48-52.

20 Cho YS, Kim CG, Kim WB, Kim CW. Multistep photorefractive keratectomy for high myopia. Refract Corneal Surg 1993; 9 (Suppl): S37-42.

21 Waring GO III, Lynn MJ, McDonnell PJ, and the PERK Study Group. Results of the prospective evaluation of radial keratotomy (PERK) study ten years after surgery. Ophthalmology 1994; 112: 1298-308.

22 Tuft SJ, Zabel RW, Marshall J. Corneal repair following keratectomy. A comparison between conventional surgery and laser photoablation. Invest Ophthalmol Vis Sci 1989; 30: $1770-7$.

23 Caubet E. Causes of subepithelial corneal haze over 18 months after photorefractive keratectomy for myopia. Refract Corneal Surg 1993; 9 (Suppl): S65-70.

24 O'Brart DPS, Gartry DS, Lohmann C, Patmore A, Kerr Muir MG, Marshall J. Treatment of band keratopathy by excimer laser phototherapeutic keratectomy (PTK): surgical techniques and long term follow up. Brf Ophthalmol 1993; 77: 702-8.

25 Sher NA, Bowers RA, Zabel RW, Frantz JM, Eiserman RA, Brown RA, et al. Clinical use of the $193 \mathrm{~nm}$ excimer laser in the treatment of corneal scars. Arch Ophthalmol 1991; 109: 491-8.

26 Munnerlyn CR, Koons SJ, Marshall J. Photorefractive keratectomy: a technique for laser refractive surgery. tectomy: a technique for laser refrac
f Cataract Refract Surg 1988; 14: 46-52.

27 O'Bratart DPS, Gartry DS, Lohmann C, Kerr Muir MG, Marshall J. Excimer laser photorefractive keratectomy for myopia: comparison of $4.00 \mathrm{~mm}$ and $5.00 \mathrm{~mm}$ ablation zones. F Refract Corneal Surg 1994; 10: 87-94.

28 O'Brart DPS, Lohmann CP, Klonos G, Corbett MC, Pollock WST, Kerr Muir MG, et al. The effects of topical corticosteroids and plasmin inhibitors on refractive outcome, haze and visual performance after photorefractive keratectomy: a prospective randomised observer-masked study. Ophthalmology 1994; 101: 1565-74.

29 Corbett MC, O'Brart DP, Marshall J. Do topical corticosteroids have a role following excimer laser photorefractive keratectomy?. F Refract Corneal Surg 1995; 11: 380-7.

30 Lohmann C, Timberlake GT, Fitzke FW, Gartry DS, Kerr Muir MG, Marshall J. Corneal light scattering after 
excimer laser photorefractive keratectomy: the objective measurement of haze. Refract Corneal Surg 1992; 8: 114-21.

31 Lohmann C, Gartry DS, Kerr Muir MG, Timberlake GT, Fitzke FW, Marshall J. 'Haze' in photorefractive keratectomy: origins and consequences. A review. Lasers and Light Ophthalmol 1991; 4: 15-34.

32 Lohmann C, Fitzke FW, O'Brart DPS, Kerr Muir MG, Marshall J. Halos - a problem for all myopes? A compariMarshall J. Halos - a problem for all myopes? A comparison between spectacles, contact lenses and photorefrac-
tive keratectomy. Refract Corneal Surg 1993; 9: S72-5.

33 Trokel SL, Srinivasan R, Braren B. Excimer laser surgery of the cornea. Am f Ophthalmol 1983; 96: 710-15.

34 Marshall J, Trokel S, Rothery S, Schubert H. An ultrastructural study of corneal incisions induced by excimer laser at $193 \mathrm{~nm}$. Ophthalmology 1985; 92: 749-58.

35 Puliafito CA, Steinert RF, Deutsch TF, Hillenkamp F, Dehm EJ, Adler CM. Excimer laser ablation of the cornea and lens. Ophthalmology 1985; 92: 741-8.

36 Simon G, Ren Q. Biomechanical behaviour of the cornea and its response to radial keratotomy. $\mathcal{F}$ Refract Corneal Surg 1994; 10: 343-56.

37 Bryant MR, Szerenyi K, Schmotzer H, McDonnell PJ. Corneal tensile strength in fully healed radial keratotomy wounds. Invest Ophthalmol Vis Sci 1994; 35: 3022-31.

38 Hanna KD, Pouliquen Y, Waring GO, Savoldelli M, Cotter $\mathrm{J}$, Morton $\mathrm{K}$, et al. Corneal stromal wound healing in rabbits after 193nm excimer laser ablation. Arch Ophthalmol 1989; 107: 895-901.

39 Krueger RR, Trokel SL. Quantification of corneal ablation by ultraviolet laser light. Arch Ophthalmol 1985; 103: 1741-2.

40 Campos $M$, Wang XW, Hertzog L, Lee M, Clapham T, Trokel SL, et al. Ablation rates and surface ultrastructure of $193 \mathrm{~nm}$ excimer laser keratectomies. Invest Ophthalmo Vis Sci 1993; 34: 2493-500.

41 Dehm EJ, Puliafito CA, Alder CM, Steinert RF. Corneal endothelial injury in rabbits following excimer laser ablation at 193 and $248 \mathrm{~nm}$. Arch Ophthalmol 1986; 104: tion at $1364-8$.

42 Carones F, Brancato R, Venturi E, Morico A. The corneal endothelium after myopic excimer laser photorefractive keratectomy. Arch Ophthalmol 1994; 112: 920-4.

43 Perez-Santonja J, Meza J, Moreno E, Garcia-Hernandez MR, Zato MA. Short-term corneal endothelial changes after photorefractive keratectomy. $\mathcal{F}$ Refract Corneal Surg 1994; 10 (Suppl): 194-8.

44 Holme RJ, Fouraker BD, Schanzlin DJ. A comparison of en face and tangential wide-area excimer surface ablation in face and tangential wide-area excimer surface

45 McDonald MB, Beuerman R, Falzoni W, Rivera L, Kaufman HE. Refractive surgery with the excimer laser Am f Ophthalmol 1987; 103: 469 .

46 Srinivasan R, Sutcliffe E. Dynamics of the ultraviolet laser ablation of corneal tissue. Am $\mathcal{F}$ Ophthalmol 1987; 103 470-1.

47 Sinbaxy A, McDonnell PJ, Moreira H. Surface ultrastructure after excimer laser ablation: expanding vs contracting apertures. Arch Ophthalmol 1991; 109: 1531-3.

48 Sher NA, Barak M, Daya S, DeMarchi J, Tucci A, Hardten $\mathrm{DR}$, et al. Excimer laser photorefractive keratectomy in
high myopia. Am $₹$ Ophthalmol 1992; 110: 935-43.

49 Heitzmann J, Binder PS, Dassar BS, Nordan LT. The correction of high myopia using the excimer laser. Arch Ophthalmol 1993; 111: 1627-34.

50 Scialdone A, Carones F, Bertuzzi A, Brancato R Randomised study of single vs double exposure in myopic PRK. Refract Corneal Surg 1993; 9 (Suppl): S41-3.

$51 \mathrm{Kim} \mathrm{JH}, \mathrm{Hahn}$ TW, Lee YC, Sah WJ. Clinical experience of two-step photorefractive keratectomy in 19 eyes with high myopia. Refract Corneal Surg 1993; 9 (Suppl): S44-7.

52 Rogers CM, Lawless MA, Cohen PR. Photorefractive keratectomy for myopia of more than -10 diopters. $\mathcal{F}$ Refract Corneal Surg 1994; 10 (Suppl): 171-3.

53 Dausch D, Klein R, Schröder E, Dausch B. Excimer laser photorefractive keratectomy with tapered transition zone for high myopia. A preliminary report of six cases. Cataract Refract Surg 1993; 19: 590-4.

54 Mandel ER, Krueger RR, Puliafito CA, Steinert RF. Excimer laser large area ablation of the cornea. Invest Ophthalmol Vis Sci 1987; 28 (suppl): 275.

55 Fantes FE, Hanna KD, Waring III GO, Poulizuen Y, Thompson KP, Savoldelli M. Wound healing after excimer laser keratomileusis (photorefractive keratectomy) in monkeys. Arch Ophthalmol 1990; 108: 665-75.

56 Taylor DM, L'Esperance FA, Del Pero RA, Roberts AD, Gigstad JE, Klintworth G, et al. Human excimer laser lamellar keratectomy: a clinical study. Ophthalmology 1989; 96: 654-64.
57 O'Brart DPS, Lohmann C, Fitzke FW, Smith SE, Kerr Muir MG, Marshall J. Night vision after excimer laser photorefractive keratectomy: haze and halos. Eur $\mathcal{f}$ Ophthalmol 1994; 4: 43-51.

58 O'Brart DPS, Lohmann CP, Fitzke FW, Klonos G, Corbett MC, Kerr Muir MG, et al. Disturbances in night vision after excimer laser photorefractive keratectomy. Eye 1994; 8: $46-51$.

59 Roberts CW, Koester CJ. Optical zone diameters for photorefractive corneal surgery. Invest Ophthalmol Vis Sci 1993; 34: 2275-81.

60 Maurice DM. The structure and transparency of the cornea. F Physiol 1957; 136: 263-86.

61 Hogan MJ, Alvorado JA, Weddel JE. The cornea. In: Histology of the human eye: an atlas and textbook. Philadelphia: Saunders, 1971.

62 Seiler $T$, Matallana $M$, Sendler $S$, Bende $T$. Does Bowman's layer determine the biomechanical properties of the cornea? Refract Corneal Surg 1992; 8: 139-42.

63 Lee RE, Davison PF, Cintron C. The healing of linear nonperforating wounds in rabbit corneas of different ages. Invest Ophthalmol Vis Sci 1982; 23: 660.

64 Davison PF, Galbavy EJ. Connective tissue remodeling in corneal and scleral wounds. Invest Ophthalmol Vis Sci 1986; 27: 1478-84.

65 Buratto L, Ferrari M, Rama P. Excimer laser intrastroma keratomileusis. Am f Ophthalmol 1992; 113: 291-5.

66 Eggli P, Boulton M, Marshall J. Growth characteristics of central and peripheral bovine corneal cells in vitro. Graefes central and peripheral bovine corneal cells in vitr

67 Tuft S, Eggli P, Boulton M, Marshall J. Assessment of corneal wound repair in vitro. Curr Eye Res 1989; 8: 713-9.

68 Gasset AR, Dohlman CH. The tensile strength of corneal wounds. Arch Ophthalmol 1968; 79: 595.

69 Melles GRJ, Binder PS. Effect of wound location, orientation, direction, and postoperative time on unsutured corneal wound healing morphology in monkeys. Refract Corneal Surg 1992; 8: 427-38.

70 Yanoff $M$, Cameron D. Human cornea organ cultures: epithelial-endothelial interactions. Invest Ophthalmol Vis Sci 1977; 16: 269-73.

71 Marshall J, Trokel S, Rothery S, Krueger RR. A comparative study of corneal incisions induced by diamond and steel knives and two ultraviolet radiations from an excimer laser. Br f Ophthalmol 1986; 70: 482-501.

72 Lohmann CP, MacRobert I, Patmore A, O'Brart DPS, Corbett MC, Kerr Muir MG, et al. A histopathological study of surgical specimens of tissue responsible for haze study of surgical specimens of tissue responsible for haze and regression after excimer laser photorefractive

73 Gordon M, Seiler T, Carey JP, Friedman MD, Johnsson NMF, King MC, et al. Photorefractive keratectomy (PRK) at $193 \mathrm{~nm}$ using an erodible mask: new developments and clinical progress. SPIE Proc 1993: 1877.

74 Brancato R, Carones F, Trabucchi G, Scialdone A, Tavola A. The erodible mask in photorefractive keratectomy for myopia and astigmat

75 Taylor Laser and Research Group. Comparison of excimer laser treatment of astigmatism and myopia. Arch Ophthalmol treatment of astigm

76 Dougherty PJ, Wellish KL, Maloney RK. Excimer ablation rate and corneal hydration. Am f Ophthalmol 1994; 118: 169-76.

77 Seiler T, Genth U, Holschbach A, Derse M. Aspheric photorefractive keratectomy with excimer laser. Refract Corneal Surg 1993; 9: 166-72.

78 Fleming JF. Should refractive surgeons worry about corneal asphericity? Refract Corneal Surg 1990; 6: 455-7.

79 Seiler T, Reckmann W, Maloney RK. Effective spherical aberration of the cornea as a quantitative descriptor in corneal topography. F Cataract Refract Surg 1993; 19 (Suppl): 155-65.

80 Camp JJ, Maguire LJ, Cameron BM, Robb RA. A computer model for the evaluation of the effect of corneal topography on optic

81 Applegate RA, Gansel KA. The importance of pupil size in optical quality measurements following radial keratotomy. Refract Corneal Surg 1990; 6: 47-54.

82 Holladay JT, Lumm MJ, Waring III GO, Gemmil $M$, Keehn GC, Fielding B. The relationship of visual acuity, refractive error; and pupil size after radial keratotomy. Arch Ophthalmol 1991; 109: 70-6.

83 Durrie DS, Lesher MP, Cavanaugh TB. Classification of variable clinical response after myopic photorefractive keratectomy. $\mathcal{F}$ Refract Corneal Surg 1995; 11: 341-7. 